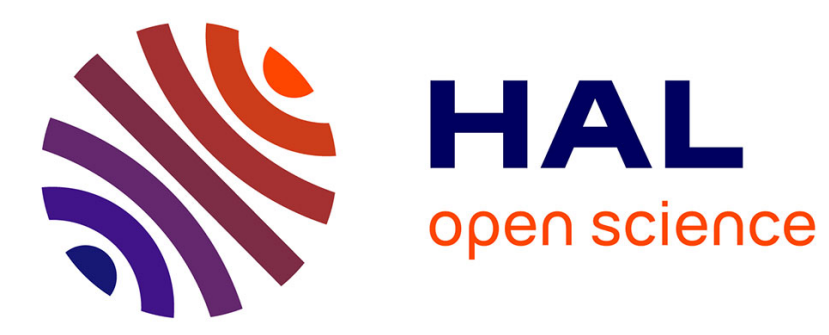

\title{
TRANSPORT PHENOMENA AND REACTOR DESIGN FOR CHROMIUM CARBIDE DEPOSITION
}

\author{
M. Pons, M. Sancandi, J. Nowak
}

\section{To cite this version:}

M. Pons, M. Sancandi, J. Nowak. TRANSPORT PHENOMENA AND REACTOR DESIGN FOR CHROMIUM CARBIDE DEPOSITION. Journal de Physique IV Proceedings, 1991, 02 (C2), pp.C2111-C2-118. 10.1051/.jp4:1991213 . jpa-00249800

\section{HAL Id: jpa-00249800 https://hal.science/jpa-00249800}

Submitted on 1 Jan 1991

HAL is a multi-disciplinary open access archive for the deposit and dissemination of scientific research documents, whether they are published or not. The documents may come from teaching and research institutions in France or abroad, or from public or private research centers.
L'archive ouverte pluridisciplinaire HAL, est destinée au dépôt et à la diffusion de documents scientifiques de niveau recherche, publiés ou non, émanant des établissements d'enseignement et de recherche français ou étrangers, des laboratoires publics ou privés. 


\title{
TRANSPORT PHENOMENA AND REACTOR DESIGN FOR CHROMIUM CARBIDE DEPOSITION
}

\author{
M. PONS*, M. SANCANDI ${ }^{*}$ and J.F. NOWAK \\ UNIREC, BP. 70, F-42702 Firminy, France \\ *Laboratoire S2MC, U.R.A. CNRS $N^{\circ}$ 413, ENSEEG, BP.75, \\ F-38402 Saint-Martin d'Hères, France \\ *DT21, Chemin des Prèles, F-38240 Meylan, France
}

\begin{abstract}
In recent years, considerable effort has been devoted to the development of computer codes being able to simulate the CVD process. Improved modelling techniques and better understanding of reaction and transport phenomena during deposition are needed to bridge the gap between general knowledge and new process requirements. The general finite element code Flux Expert has been adapted to heat and mass transfer problems in CVD. With built in graphics and fully interactivity, a broad range of users may easily solve some of their CVD problems. Our aim in the example presented was to simulate the growth rate uniformity of chromium carbide coatings deposited inside a tube from organometallic precursors. We clearly show the influence of the injector geometry on the uniformity. Even if the chemistry of the examples discussed was simple, the agreement between experimental and theoretical values is rather good; the two dimensional approximation of the hole bored injector seems also to be adequate to describe the geometry.
\end{abstract}

\section{1.-Introduction}

Today's modern technology requires to produce corrosion and/or wear resistant coatings with a high reliability. To meet these requirements, a considerable effort has been devoted to the development of computer codes capable of modelling chemical vapor deposition and etching processes [1-14]. The purpose of this effort is to provide a better understanding of coupled phenomena because the performances of reactors are depending on a wide range of variables. The geometric configuration of the reactor, the operating conditions are intimately related to the kinetics of the film growth. It is important to note that, for the most part, the design of industrial equipment have been made empirically and cannot guarantee optimum conditions. Software packages can provide a highly cost effective, speedy path to process optimization and process development [2]. The predictions which come from these models are limited (perhaps except for Si deposition from silane) by an incomplete knowledge of the chemical phenomena (chemical reactions either in the gas phase or on the substrate) [1].

In order to reach some insight for the development of new reactor configurations we have adapted the general finite element code Flux Expert [4] to heat and mass transfer problems in CVD. We have chosen a general code because CVD problems are numerous and the chosen code can be easily modified and upgraded.

The aim of this study was to design a reactor for chromium carbide deposition inside and outside tubes (figure 1). We will show that a two dimensional approximation of complex injectors gives a good agreement with experimental results. To modify the deposition area, while maintaining good film uniformity is a complex problem because poorly designed injectors can lead to high thickness variations. Our primary goal of the modelling strategy was to uncover the important chemical and physical processes that govern the multi-radial flow reactor. Even if supercomputer technology is evolving rapidly towards being able to handle complex geometries and complex transport and chemistry coupled phenomena we have simplified the situations in order that solutions are practical. 

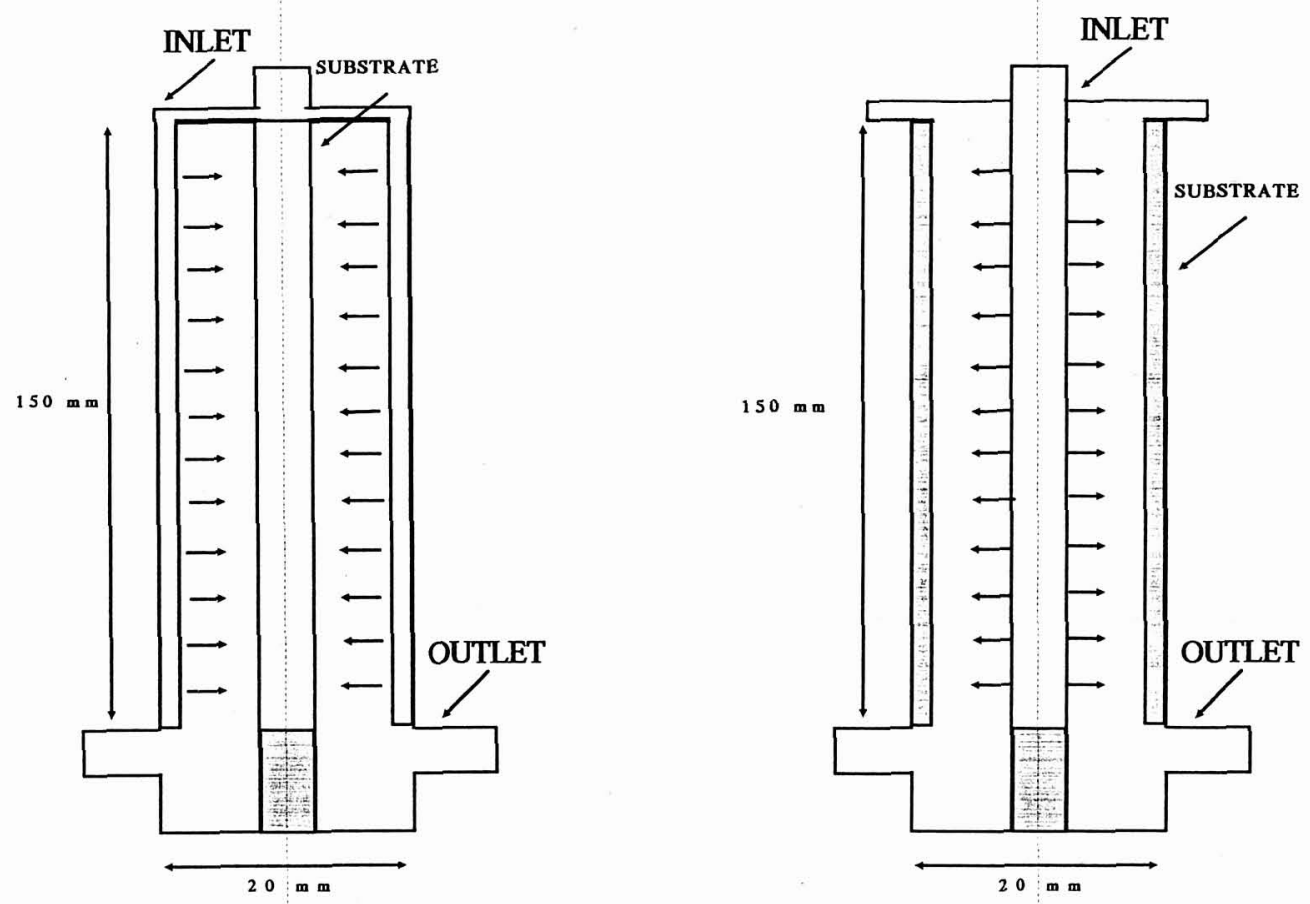

Fig.1. CVD Reactors

TABLE 1 : Data table

\begin{tabular}{|l|l|l|l|}
\hline Temperature & \multicolumn{1}{|c|}{$\mathrm{T}$} & \multicolumn{1}{|c|}{$\mathrm{K}$} & 800 \\
Density & $\rho$ & $\mathrm{kg} / \mathrm{m}^{3}$ & $0.06 \mathrm{P} / \mathrm{P}_{0}$ \\
Viscosity & $\mu$ & $\mathrm{kg} / \mathrm{ms}$ & $4.10^{-5}$ \\
Diffusivity & $\mathrm{D}$ & $\mathrm{m}^{2} / \mathrm{s}$ & $0.210^{-4} \mathrm{P}_{0} / \mathrm{P}$ \\
Surface reaction rate & $\mathrm{K}$ & $\mathrm{m} / \mathrm{s}$ & $0.01-1$ \\
Flow rate (STP) & $\mathrm{Q}$ & $\mathrm{I} / \mathrm{mn}$ & $0.2-2$ \\
Inlet mass fraction & $\mathrm{w}$ & & 0.001 \\
Reynolds number & $\mathrm{Re}$ & & $1-10$ \\
Damköhler number & $\mathrm{Da}$ & & $0.015-1.5$ \\
\hline
\end{tabular}




\section{2.-Geometries and experiments}

Carbide and nitride of transition metals, especially $\mathrm{Cr}-\mathrm{N}-\mathrm{C}$ coatings have a good behaviour against corrosion, wear and oxidation. For their deposition at low temperature, MOCVD process is a promissing technique. Recently the growth of chromium nitride and carbonitride on steel surface, using the bis benzene chromium (BBC) as chromium vapor source and $\mathrm{NH}_{3}$ or $\mathrm{N}_{2} \mathrm{H}_{4}$ as nitrogen source, has been performed [15]. Thermodynamic equilibrium calculations in the $\mathrm{Cr}-\mathrm{N}-\mathrm{C}-\mathrm{H}$ system have already shown the feasability of chromium nitride or carbonitride deposition at low temperature and reduced pressure. With classical horizontal CVD reactor there is a good agreement between experimental values and calculated CVD phase diagrams.

The modelling of mass transport phenomena, taking in account laboratory kinetic experiments, must lead to refinements concerning the role of the inlet flow. For better clarity, we only show results concerning the deposition inside tubes.

In the prototype, the reactants feed in through the center tube, which is hole bored. The gases flow axially along the center tube, changing direction to pass through the holes to flow radially towards the deposition area. This configuration appears to have several potential advantages if the injector is well designed. There is no axial depletion of the reactant gases like in classical tubular reactors where the injection flow is axial. Perhaps the main limitation would be the autodoping due to the fact that the reaction products pass over the substrate.

\section{3.-Simulation and discussion}

\section{1.-The problem}

The CVD process involves momentum, mass, energy and species balance [1]. We only consider the stationary case because the film growth rate is slow compared to the gas velocities. In our case, the organometallic precursor is diluted (mass fraction : $10^{-3}$ ) in the carrier gas $(\mathrm{He})$; it is then possible to remove the dependence of the flow on the species balance. The consumption of the reactive species is a boundary condition on the reacting areas (injector and tube). Measurements have shown that, even using cold gases at the inlet, the reactor which is in a furnace is quite isothermal. The typical working temperature is $800 \mathrm{~K}$.

Table 1 shows the physicochemical values used in the simulation and obtained from statistical mechanical calculations. To give a complete description of the modelling equations, kinetic rate expressions and transport coefficients must be specified. Because of the lack of data concerning the gas phase cracking of $\mathrm{BBC}$, we employ a one specie sdiffusion model assuming that (i) the binary diffusion coefficients are almost identical to that of the source (BBC) and (ii) all cracking gas species have the same probability of heterogeneous reaction. We assumed that one effective overall surface reaction governs the mass transfer. A first order surface reaction rate constant is chosen for deposition on the central (injector) and external (substrate) tubes. The mass balance and associated boundary conditions are :

$$
\begin{aligned}
& \operatorname{div}(\vec{v} \rho w-D \overrightarrow{g r a d} \rho w)=0 \\
& -D \overrightarrow{\operatorname{grad}} \rho w \cdot \vec{n}=k_{i} \rho w
\end{aligned}
$$

on the reactive surfaces ( $\mathrm{i}=\mathrm{a}$ for the central injector tube; $\mathrm{i}=\mathrm{t}$ for the external tube). The deposition rate $(G)$ is calculated from mass deposited flux :

$$
\mathrm{G}=(\mathrm{D} \overrightarrow{\mathrm{grad}} \rho \mathrm{w} \cdot \overrightarrow{\mathrm{n}}) \mathrm{M}_{\mathrm{s}} /\left(\mathrm{M}_{\mathrm{r}} \rho_{\mathrm{s}} \propto\right)
$$

where $M_{s}$ is the molecular weight of the solid, $M_{r}$ is the molecular weight of the BBC, $\rho_{s}$ is the density of the solid and $\alpha$ the stoichiometric coefficient of the chemical reaction. (For the MOCVD growth of $\mathrm{Cr}_{7} \mathrm{C}_{3}, M_{\mathrm{s}}=428 \mathrm{~g}, \mathrm{M}_{\mathrm{r}}=212 \mathrm{~g}, \rho_{\mathrm{s}}=6.2 \mathrm{~g} / \mathrm{cm}^{3}, \alpha=7$ ). 
The geometry of the reactor, due to the hole bored inlet tube is three dimensional. We have assumed that the 9 or 11 rings each containing 4 holes of $1 \mathrm{~mm}$ diameter are open rings of the same area as the 4 holes. This assumption allows to simplify the 3D geometry to a 2D axisymetric one. A 20×150 irregular grid mesh has been used (30 grid nodes for each gas inlet ring).

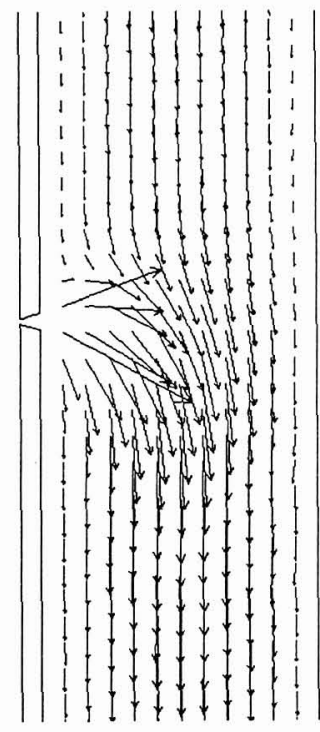

(a)

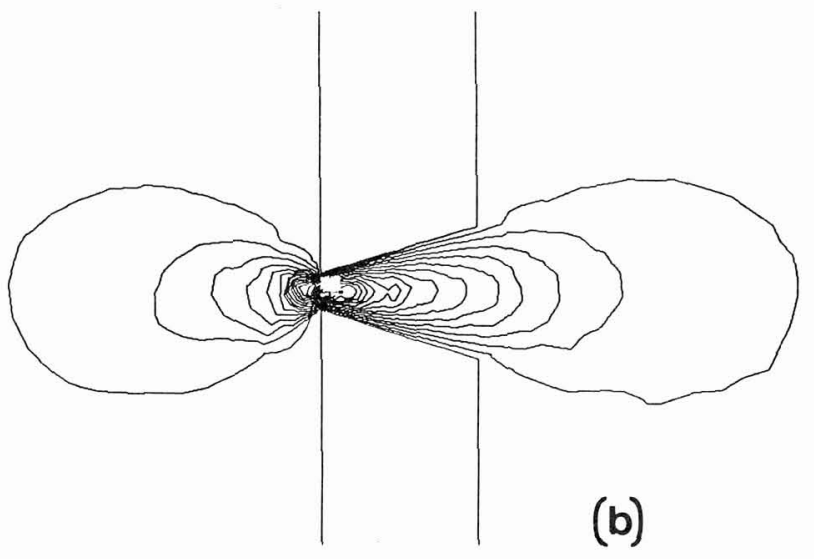

(c)

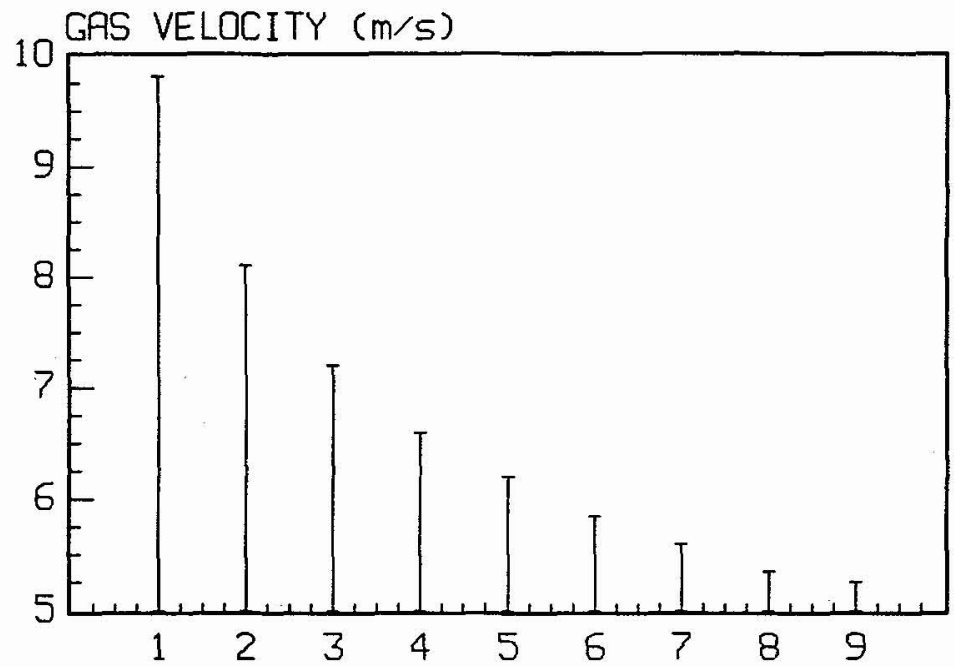

RING NUMBER

Fig.2. (a) Computed velocity vectors for the reactor shown in figure 1 and operated with $0.6 \mathrm{SLM}$ at $2.6 \mathrm{kPa}$ and $800 \mathrm{~K}$ (detail of the second ring)

(b) Radial iso-velocity lines at the outlet of the second ring

(c) Radial velocities at the outlet of the central injector 


\section{2.-Results}

The aim of the modelling strategy is to fit experimental and theoretical results in order to determine if the assumptions (geometry and kinetics) are valid. After, we will give general trends concerning the apparatus.

Figure 2 shows the velocity field in the 2D simplified geometry. The radial velocity near the rings outlet is not uniform and could make the convective mass transport irregular. In the 0.6-2 SLM inlet flow rate range and in the $0.6-8 \mathrm{kPa}$ pressure range the same gas flow patterns were found for radial velocities at the outlet rings.

The figure 3 shows the calculated thickness of the coatings for differents conditions. Figure 3(a) shows that for high inlet flow rate, the radial flow at the central tube outlet is so high that convective mass transport is predominant in front of the rings. For lower inlet flow rate and lower pressure more uniform films are achieved (figures 3b, 3c). The calculated growth rate profiles are in better agreement with experimental results when deposition is considered to occur not only on the external tube but also on all metallic areas of the reactor (experimentally observed). If the injector and walls are considered to be non reactive, the calculated thickness profile does not agree with experimental results in the first part of the substrate. When the pressure is lowered, the growth rate is lowered but the homogeneity is better. The distributions of the BBC concentration are shown in figure 4. The values of $k_{i}\left(k_{2}=k_{t}\right)$ have been fitted to match experiments $(k=0.12 \mathrm{~m} / \mathrm{s})$ Recalling that the deposition reaction is considered to be of first order, it is possible to evaluate a dimensionless quantity, the Damköhler surface reaction number [1] defined as $D a$ $=\mathrm{R}_{\text {ref }} \mathrm{L} / \mathrm{C}_{\text {ref }} \mathrm{D}$ with $\mathrm{R}_{\text {ref }}=\mathrm{k} \rho \mathrm{w}_{0}, \mathrm{C}_{r e f}=\rho \mathrm{w}_{0}$ with $\mathrm{w}_{0}$ the inlet mass fraction and $\mathrm{L}$ the characteristic length of the reactor. This number is a useful measure of the characteristic time for diffusion to surface to the characteristic time for surface reaction. As we can see in figure 5 with large $\mathrm{Da}$ values (high pressure) the uniformity is seen to worsen in the first part of the substrate. At low Da values, the growth rate is lowered, but the film uniformity is improved ; the gas flow pattern slightly influences the growth rate as with large Da values.

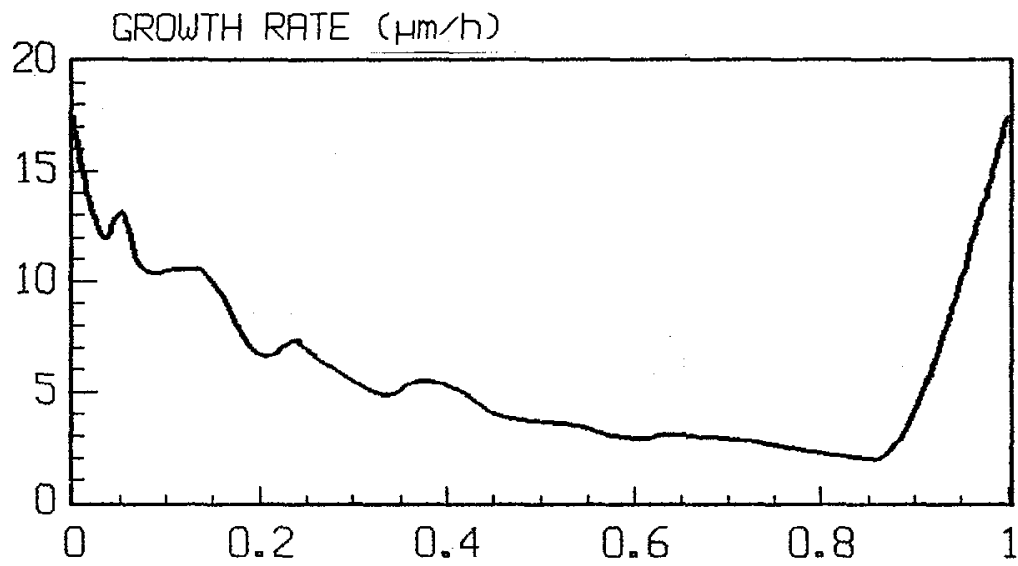

REDUCED TUBE LENGTH $(\mathrm{L}=0.11 \mathrm{~m})$

Fig.3. (a) Growth rate along the tube $P=7.9 \mathrm{kPa} ; \mathrm{Q}=2 \mathrm{SLM} ; \mathrm{w}=0.001$ 


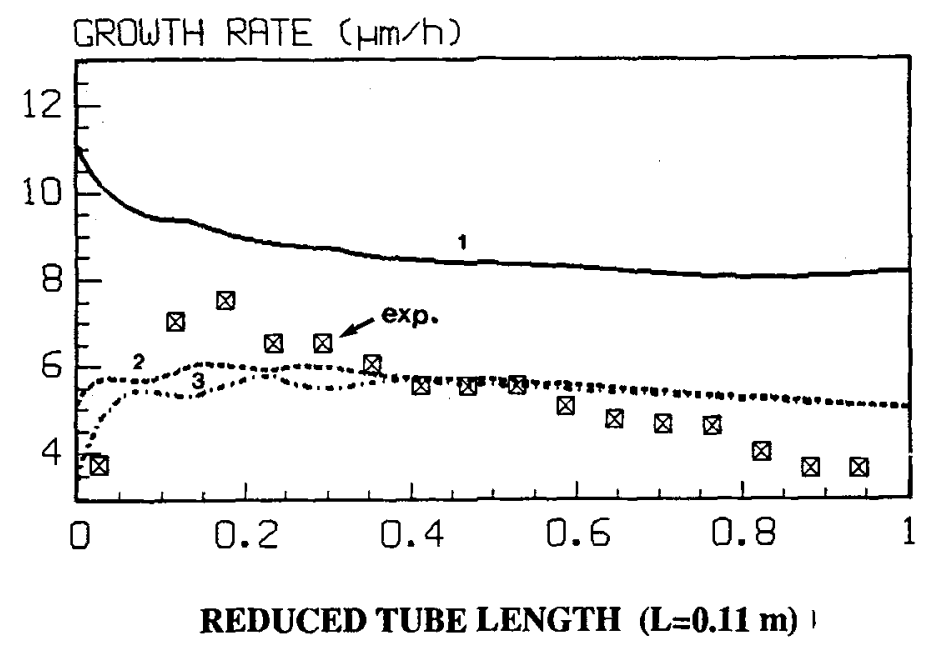

Fig.3. (b) Growth rate along the tube :

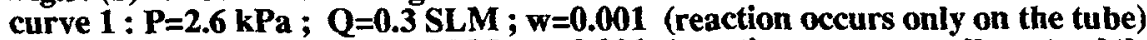
curve $2: P=2.6 \mathrm{kPa} ; \mathrm{Q}=0.3 \mathrm{SLM} ; \mathrm{w}=0.001$ (reaction occurs on all parts of the reactor) curve $3: P=2.6 \mathrm{kPa} ; \mathrm{Q}=0.3 \mathrm{SLM} ; \mathrm{w}=\mathbf{0 . 0 0 1}$ (reaction occurs on all parts of the reactor and the position of the rings has been lowered)



Fig.3. (c) Growth rate along the tube $P=0.65 \mathrm{kPa} ; \mathrm{Q}=0.3 \mathrm{SLM} ; \mathrm{w}=0.001$ (reaction occurs on all parts of the reactor) 


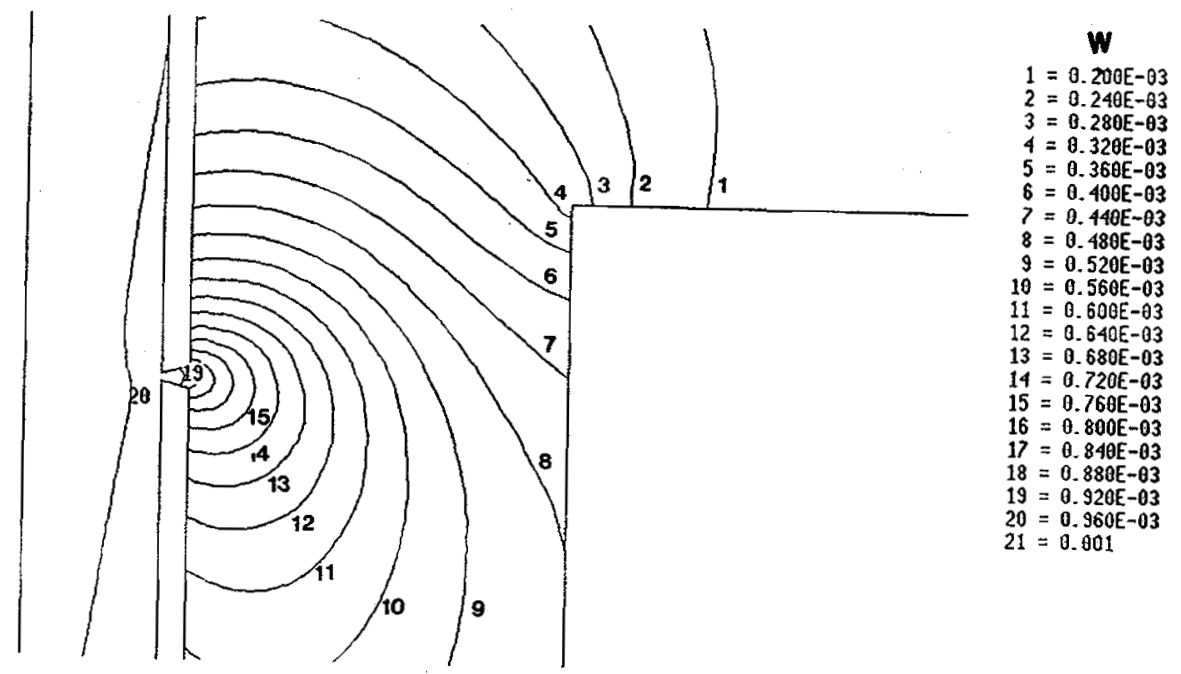

Fig.4. Isoconcentration lines for the conditions of figure 3(b) curve 2 (detail of the first ring)

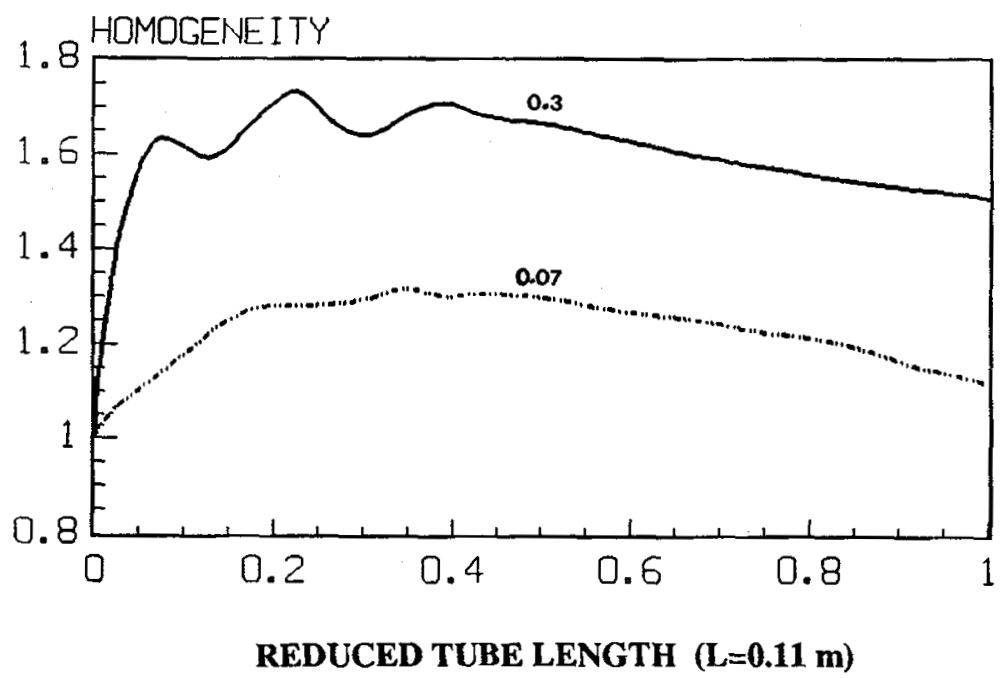

Fig.5. The effects of the Damköhler number on the homogeneity 


\section{4.-Conclusions}

A mathematical model and assumptions are proposed for the calculation of the flow and concentration fields in a complex reactor. The chemistry of the examples discussed in this paper was quite simple. Only one chemical reaction was assumed to be important. However, these simulations have shown that the physicochemical model used seems adequate to describe the general trends of the deposition process. The agreement between the experimental data and computed deposition profile is satisfactory in the investigated range of conditions. It is also important to note that the 2D simplification of the injector seems valid; so, these preliminary results allow us to investigate several hardware configurations of the same kind prior to equipment fabrication.

\section{References}

/1/ Jensen, K.F., in Hess, D.W., Jensen, K.F. (eds), Microelectronics Processing, Advances in Chemical Series 221, American Chemical Society, Washington D.C., 1989, 199.

12/ Szekely, J., J. Met., 42 (2) (1990) 16.

13/ Ulacia, J.I., Werner, Ch., Solid State Technol, 33 (11) (1990) 107.

141 Pons, M., Klein, R., Arena, C., Mariaux, S., J. Phys. Coll. C5, 50 (1989) 57.

15/ Kleijn, C.R., Hoogendoorn, C.J., Chem. Eng. Sci., 46 (1) (1991) 321.

16/ Moffat, H.K., Jensen, K.F., J. Electrochem. Soc., 135 (1988) 459.

17 I Ouazzani, J., Rosenberger, F.J., Crystal Growth, 100 (1990) 545.

181 Gokuglu, S.A., in Spear, K.E., Cullen, G.W. (eds.), Proc. $11^{\text {th }}$ Chemical Vapor Deposition Conference, The Electrochemical Society, Pennington, NJ, 90 (12) (1990) 1.

19/ Holstein, W.I., Fitzjohn, J.L., J. Crystal Growth, 94 (1989) 145.

/10/ Field, R.J., J. Crystal Growth 97 (1989) 739.

/11/ Arora, R., Pollard, R., in Ref 6, 90 (12) (1990) 106.

/12/Rosner, D.E., Collins, J., in Ref 8, 90 (12) (1990) 49.

/13/ Couderc, J.P., Duverneuil, P., J. Phys. Coll. C5, 50 (1989) 35.

/14/Yoo, C.S., Dixon, A.G., J. Crystal Growth, 97 (1989) 337.

/15/ Schuster, F., Schouler, M.C., Bernard, C., Maury, F., Morancho, R., Nowak, J.F., in Ref $8,90(12)(1990) 113$. 